\title{
Boiler drum automatic power management system
}

\author{
Tatiana Efremova, and Sergey Shchegolev* \\ Balakovo Institute of Engineering and Technology of the National Research Nuclear University \\ MEPhI (Moscow Engineering Physics Institute), Chapaeva Str., 140, 413853 Balakovo, Russia
}

\begin{abstract}
Dynamic properties of boiler sections as control objects are studied. The requirements for mathematical models and the main adjustable parameters in drum boilers are determined, on the basis of which the requirements for the designed model are made. The construction of a block diagram and calculation of transfer functions of the automatic control system of the control object. The main types of disturbances are determined: feed water and steam consumption, consumer load, fuel consumption, and feed water temperature. Each perturbation is represented as a control action. Models of the object using perturbation channels are obtained. The article considers the construction of an effective model of the system of automatic control of the drum boiler power supply based on the system's working out of disturbing influences. The paper uses the Matlab application software and the Simulink graphical programming environment.
\end{abstract}

\section{Introduction}

Steam generating thermal machines are the technological base for many industrial facilities. Providing optimal modes of equipment operation, increasing reliability, reducing energy consumption, increasing cost-effectiveness, environmental friendliness, increasing power efficiency - a small part of the tasks faced by modern industrial facilities, the solution of which is possible using automatic and automated systems.

A steam boiler as a control object is a complex dynamic system with a large number of input and output interrelated values. For investigation of such system the complex mathematical model of object dynamics taking into account mutual influence of regulation loops on the object can be used.

\section{Materials and Methods}

Modeling is a rather effective and universal method of obtaining knowledge about the surrounding reality.

\footnotetext{
* Corresponding author: shchegolevs@gmail.com
} 
The model is a material or mentally imagined object, which in the process of cognition (study) replaces the original object, while retaining its most typical features characteristic of the problem solved [1].

When building a model, only those factors that are most significant for the research being conducted are taken into account [1]. Effective mathematical models in the electric power industry allow obtaining the required results confirmed in practice with a sufficient degree of accuracy.

The main requirements for mathematical models are adequacy, universality and efficiency [2].

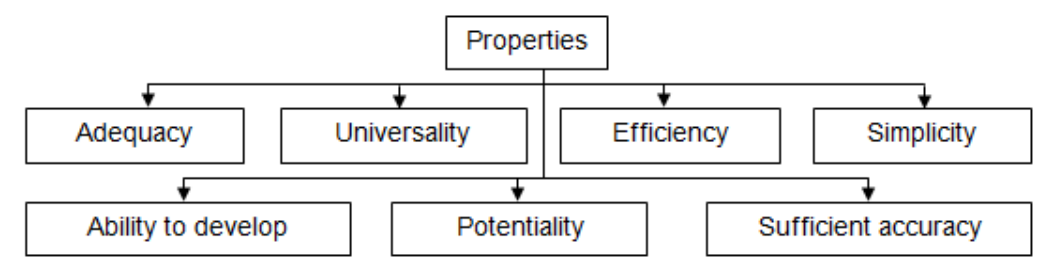

Fig. 1. Model Properties.

Adequacy. A model is considered adequate if it reflects the given properties with acceptable accuracy. Accuracy is defined as the degree of correspondence between the values of output parameters of the model and the object. Model accuracy is different in different conditions of object functioning [2].

Universality. It is defined mainly by the number and composition of external and output parameters considered in the model [2].

Efficiency. The model is characterized by the cost of computational resources for its implementation [2].

As the basic means of mathematical modeling it is possible to consider Matlab as the software tool having sufficient functionality, corresponding to considered problems.

Matlab is a package of application programs for solving technical computing problems. Simulink is a Matlab-based graphical programming environment for modeling and analyzing dynamic systems. Simulink is widely used in automatic control and digital signal processing for modeling and design. Package Simulink includes the full complex of libraries of the blocks necessary for creation of functional models of control and communication systems, digital, electrotechnical and power devices and so forth. Thus it allows to change library blocks, and also to create own [3].

\subsection{Determination of adjustable parameters in drum boilers}

Automatic regulation of the boiler unit technological process should ensure its normal operation, both in constant and transient modes in the adjustable range of loads from 40 50 to $100 \%$ of the nominal load. It should be ensured:

1. Adjusting the water level in the drum. Information about the water level in the drum is fed to the regulator input from the level sensor.

2. Regulation of fuel supply depending on the steam load of the boiler unit. Pressure in the boiler's steam line is usually used as information about the value of the mismatch between the heat and steam loads.

3. Control of rarefaction in the furnace. In case of deviation of the rarefaction, the regulator affects the efficiency of the smoke evacuator and changes the amount of flue gases evacuated from the furnace, thus matching the amount of gases produced in the furnace with the amount of gases leaving the furnace. 
4. Optimum ratio of oxygen in the flue gases. The impact on the blower changes the amount of air supplied to the furnace, restoring the excess air in the furnace space.

5. Control of overheating temperature in case of its deviation from the set point. It is carried out through the executive mechanism on the injection valve. This changes the amount of feed water entering the mixing chamber of the superheater. As a result, the overheating temperature value is restored.

Thus, there are three main tasks in the design of the boiler unit automatic control system. Namely: automatic regulation of boiler supply, automatic regulation of heat load and combustion process, automatic regulation of superheated steam temperature.

\subsection{Construction of the structural diagram and calculation of transfer functions of the system of automatic regulation of the drum boiler supply}

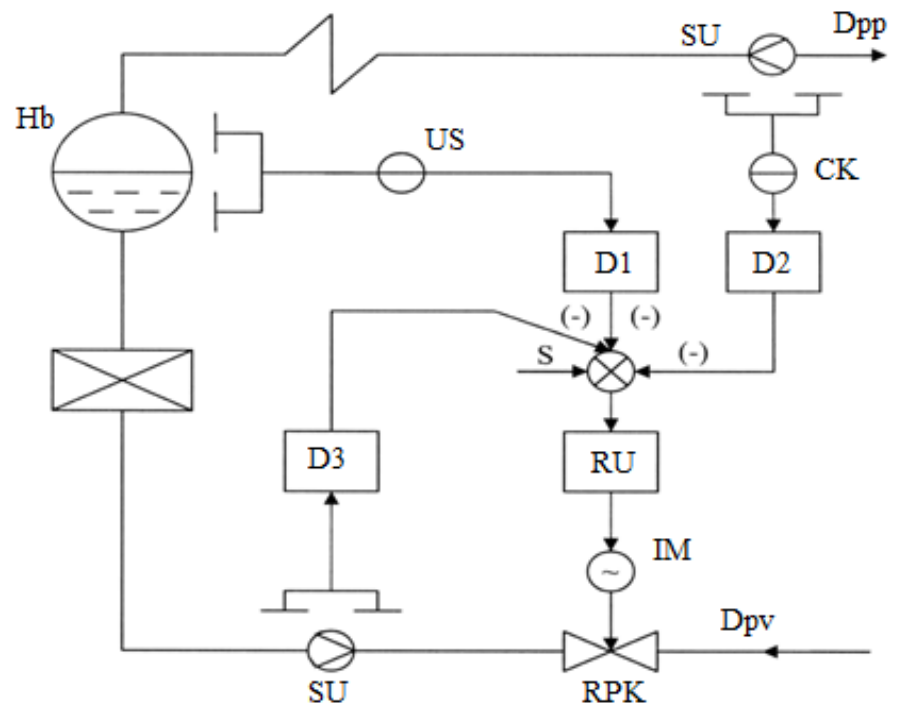

D1, D2, D3 - measuring transducers of a level of water in a drum, the expense of superheated steam, the expense of feed water; RU - the regulating device; IM - the executive mechanism; RPK - the regulating feed valve; SU - narrowing devices for measurement of the expense of water and steam; US - equalizing vessel; CK - condensation vessel; $\mathrm{S}$ - setting influence; $\mathrm{Hb}$ - water level in a steam generator drum; Dpp - the expense of superheated steam; Dpv - the expense of nutritious water; E - economizer.

Fig. 2. Structural diagram of three-pulse regulation of drum boiler water supply.

A signal characterizing the level in the drum is added to the job signal. At a new steam flow rate, the corresponding signal at the inlet to the control unit is immediately changed and the supply water flow is proportionally changed to the assumed level change. In such Automatic Regulation System, the pulses are the steam flow rate after the superheater and the water flow rate to the economizer, the level in the boiler drum, measured by the corresponding sensors.

When one of these values is changed, the regulator, acting through the executive mechanism on the regulator, changes the water flow towards maintaining the material balance and level.

1. Calculation of the level converter. The level transmitter is used as a level measuring device in the boiler drum. 


$$
\mathrm{K}_{n}=\mathrm{K}_{d m} \cdot \mathrm{K}_{o t}
$$

where $K_{d m}$ is the transmission factor of the diphomanometer; $K_{\mathrm{ot}}-$ gear ratio of the selected device.

$$
\mathrm{K}_{d m}=\frac{\Delta I}{\Delta H}=0.008
$$

where $\Delta \mathrm{I}$ is a change in the value of the level sensor output signal; $\Delta \mathrm{H}-$ level difference.

The transmission factor of the selection device (equalizing vessel with partially heated plus line) is calculated by the formula:

$$
\mathrm{K}_{o t}=0.97-0.0009 \frac{D_{\max }+D_{\min }}{2}=0.97-0.0009 \frac{103.7+31.1}{2}=0.91
$$

where $\mathrm{D}_{\max }$ is the maximum steam generator capacity, $\mathrm{kg} / \mathrm{s} ; \mathrm{D}_{\min }$ - minimum steam capacity of the steam generator, $\mathrm{kg} / \mathrm{s}$.

$$
\begin{gathered}
D_{\min }=0.3 \cdot D_{\max }=0.3 \cdot 103.68=31.104 \mathrm{~kg} / \mathrm{s} . \\
\mathrm{K}_{n}=0.91 \cdot 0.008=0.00728
\end{gathered}
$$

2. Calculation of measuring transducers for feed water and superheated steam flow.

To determine the transfer coefficients of the sets, a graph of the dependence of current on flow is drawn (Figure 3.b).

Determine the required transmission ratios of feed water and superheated steam flow sensors by the formula:

$$
K=\frac{\Delta I}{\Delta Q}=0.0125
$$

where $\Delta$ is an increase in current and flow.
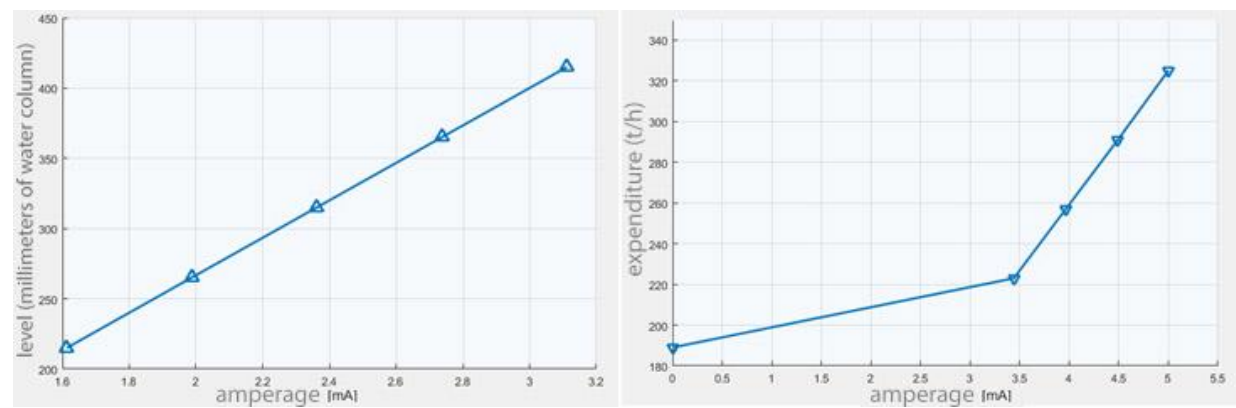

Fig. 3. Static Characteristics of Differential Manometer (a), Flow Converter (b).

3. Calculation of measuring transducers for feed water temperature.

As a basis for simulation of the signal from the sensor, the data of the KTXA type sensor with accuracy symbol k1H25 are used. With built-in transmitter model PR 5337.

Determine the required transmission ratios of the sensor of feed water temperature by the formula:

$$
K=\frac{\Delta I}{\Delta T}=0.0175
$$


Let's present a static temperature sensor characteristic in Figure 3.a, based on the sensor passport data.
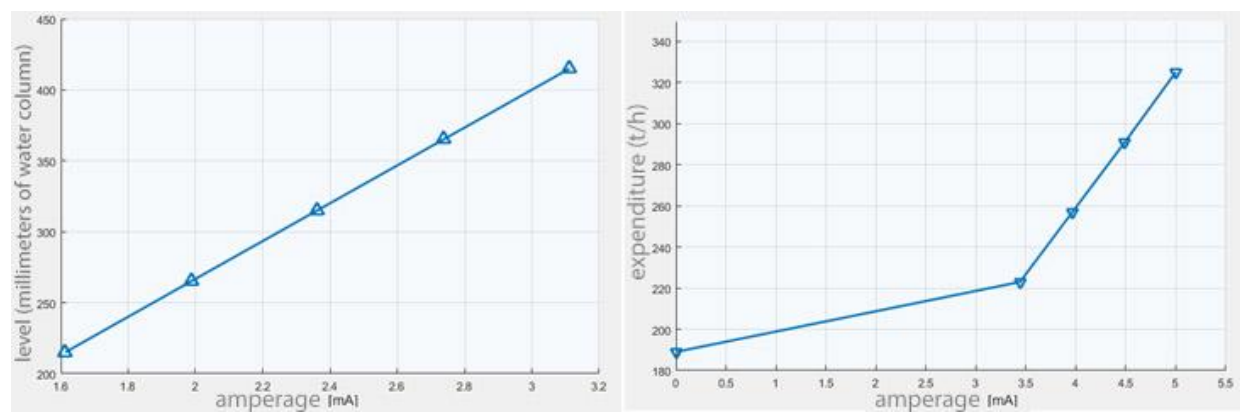

Fig. 4. Static characteristic of the temperature transmitter (a) regulating the feed valve (b).

\section{Calculation of the regulator}

The control valve characterizes the performance of the automatic level control system at various perturbation influences. It is believed that to ensure normal operation of the object at rated capacity, the flow capacity of the feed valve should be $10 \%$ more than the nominal boiler capacity. Feeder valves of modern design on high pressure boilers and rotary valves on medium pressure boilers meet these conditions.

At modelling the element can be described by a proportional link with proportionality factor $K_{\mathrm{po}}(\mathrm{kg} / \mathrm{s}) / \%$. From Figure 3 it can be seen that the characteristic of the line in the flow range of $10-84 \mathrm{~kg} / \mathrm{s}$, respectively, at $20-84 \%$.

5. The pipeline, because of a small length of a section and incompressibility of environment, from the valve to a boiler, is simulated by an inertial link of the 1st order with factor of transfer $K_{\text {tr }}=1$ and constant time $T_{\text {tr }}=1 \mathrm{~s}$.

Figure 5 shows a model of a section with a regulator and a link simulating the operation of the pipeline.

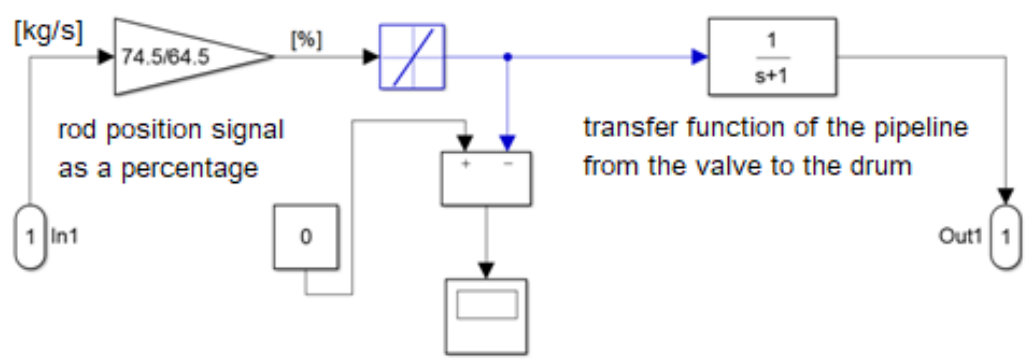

Fig. 5. Model pipeline section with regulator.

\subsection{Getting the transfer functions of the control object of the automatic regulation system}

The boiler unit is a multi-circuit control object. The control object will have five transfer functions depending on the input perturbation, or their sums, according to the superposition principle (figure 6). 


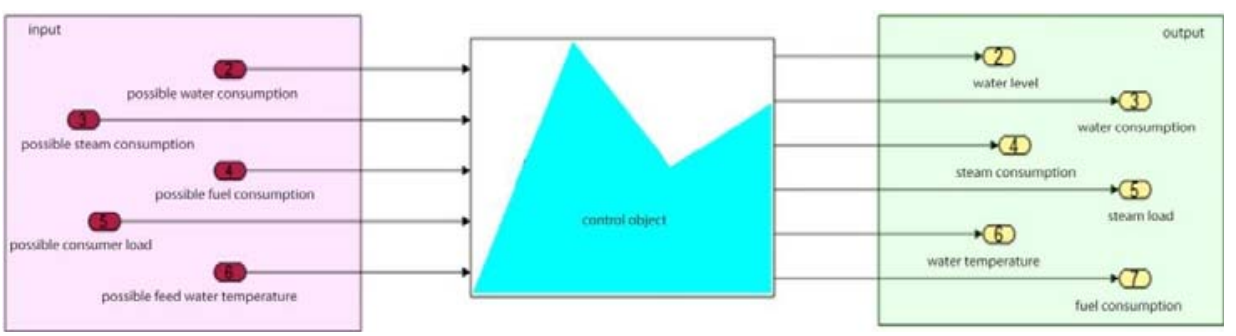

Fig. 6. Impacts on the control object.

Considered each perturbation as a control effect

1. Perturbation at feed water and steam consumption

Figure 7,a shows a model of the object through the perturbation channel of feed water and steam consumption. Characteristics of the "water flow - level" channel is shown in Figure 7.b.

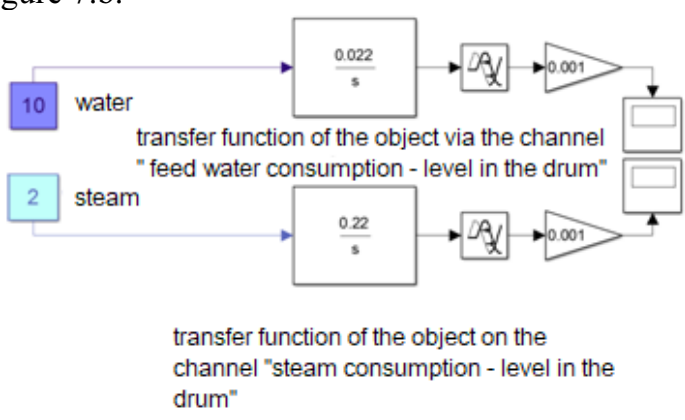

a

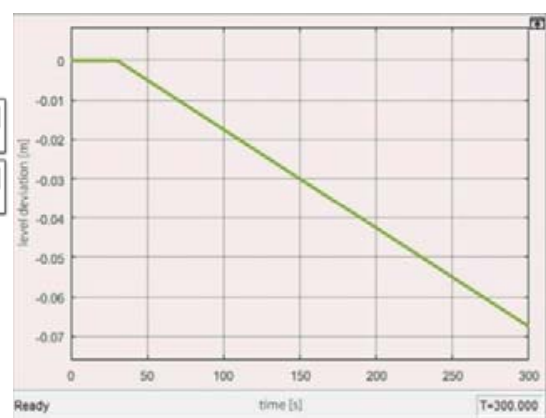

6

Fig. 7. Object model through perturbation channels by flow rate (a) and time characteristic, at supply of perturbation with feed water flow rate $10 \mathrm{~kg} / \mathrm{s}(\mathrm{b})$.

\section{User load perturbation}

A change in the load of the consumer at a stable fuel consumption causes the boiler pressure to deviate. As the load increases, the pressure in the drum drops, which causes a corresponding increase in the specific volume of steam and steam-water mixture.

Figure 8 shows the type of transfer function through the channel "consumer load level". Fig. 8,b shows the time characteristics.

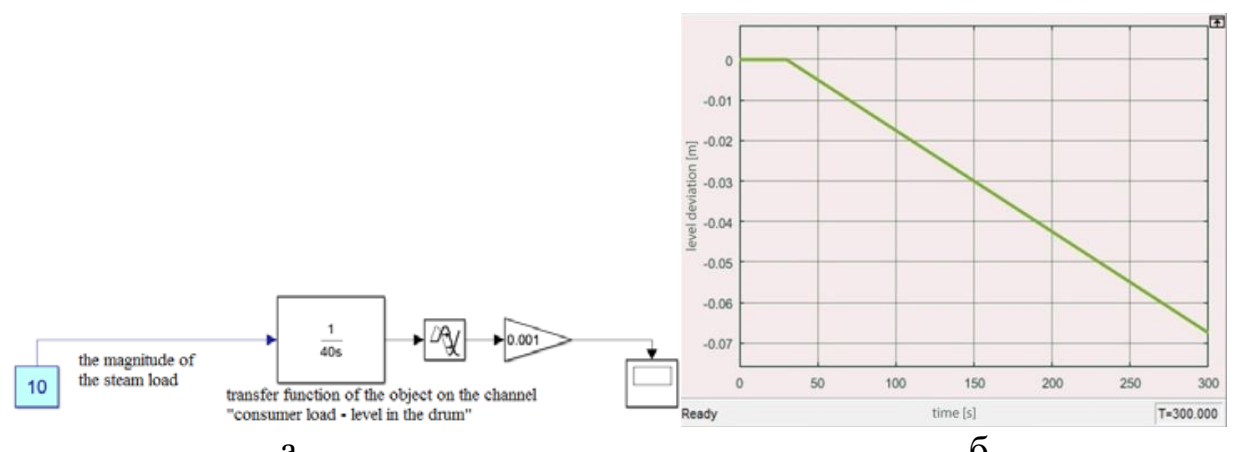

a

6

Fig. 8. Object model through perturbation channels by flow rate (a) and time characteristic, at supply of perturbation with feed water flow rate $10 \mathrm{~kg} / \mathrm{s}(\mathrm{b})$.

3. Perturbation at fuel consumption 
When fuel consumption changes and feed water consumption is constant, the nature of the transition process describing the level is similar to the process in which the perturbation is caused by the change in consumer load. The model of the transfer function through the considered perturbation channel is shown in Fig. 9,a. The time characteristic is shown in Fig. 9.b.
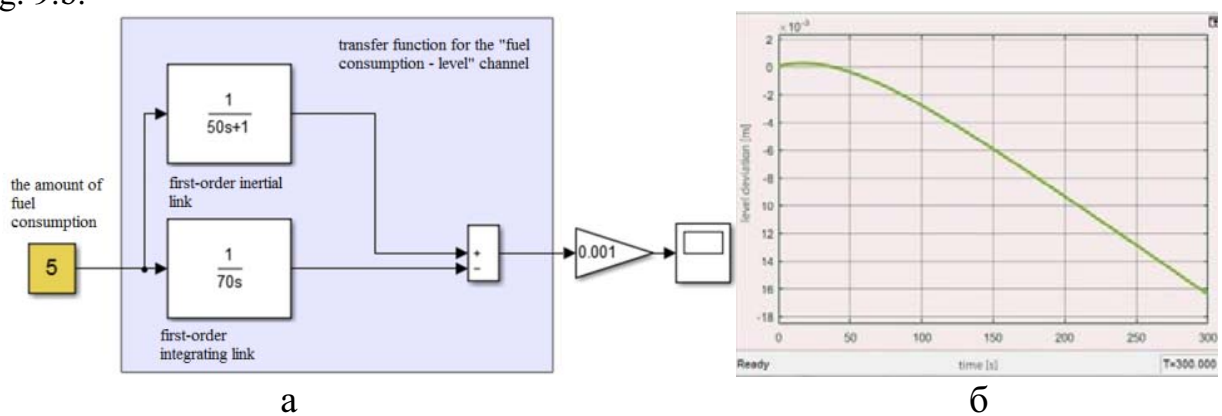

Fig. 9. Transfer function of the object through the channel "fuel consumption - level" (a) and Time characteristics of the object through the channel "fuel consumption - level" (b).

4. Perturbation at feed water temperature

When the number of regenerative heaters in operation changes, the feed water temperature changes, which leads to a change in the operating mode of the economizer.

When the water temperature to the boiler changes and the boiler is continuously heated, the vapour formation in the evaporation circuit increases. As a result, the level in the drum will increase. The model of the object is shown in Figure 10.

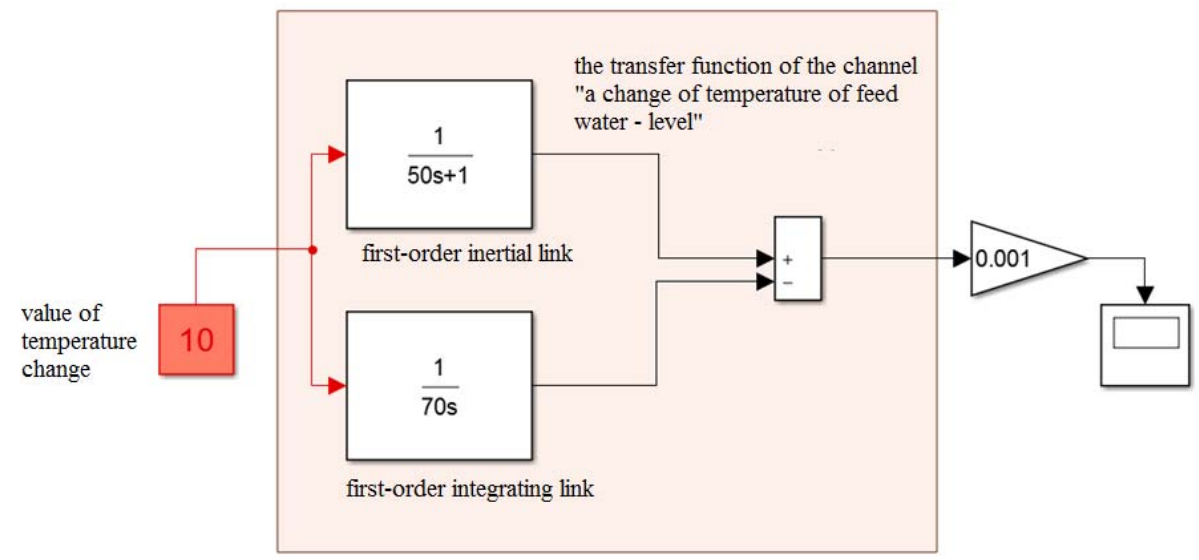

Fig. 10. Transfer function of the object through the channel "fuel consumption - level" (a) and Time characteristics of the object through the channel "fuel consumption - level" (b).

\section{Results and Discussion}

After formation of transfer functions of objects through all main supply perturbation channels, a common ARS model (Figure 10) is constructed with perturbations: water and steam consumption to the boiler, consumer load, fuel consumption and feed water temperature perturbation. 


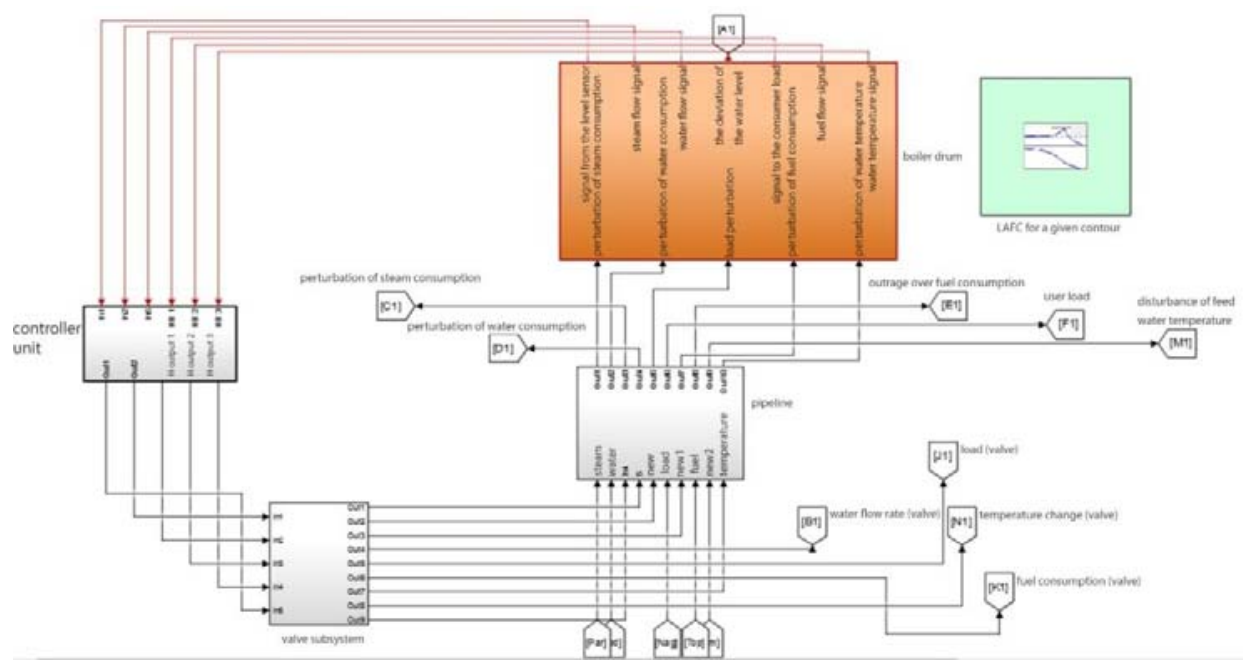

Fig. 11. General view of the model of multi-pulse boiler supply control system.

It is necessary to consider each of the blocks separately. Figure 11 shows the subsystem "Boiler drum" without "mask".

Data come to the block from the "Pipeline" subsystem, the input signals are shown in green.

From the outputs of the unit, the data of the "first level" model are fed to the "Controller" subsystem. Signals of feedback received by the controller are shown in red.

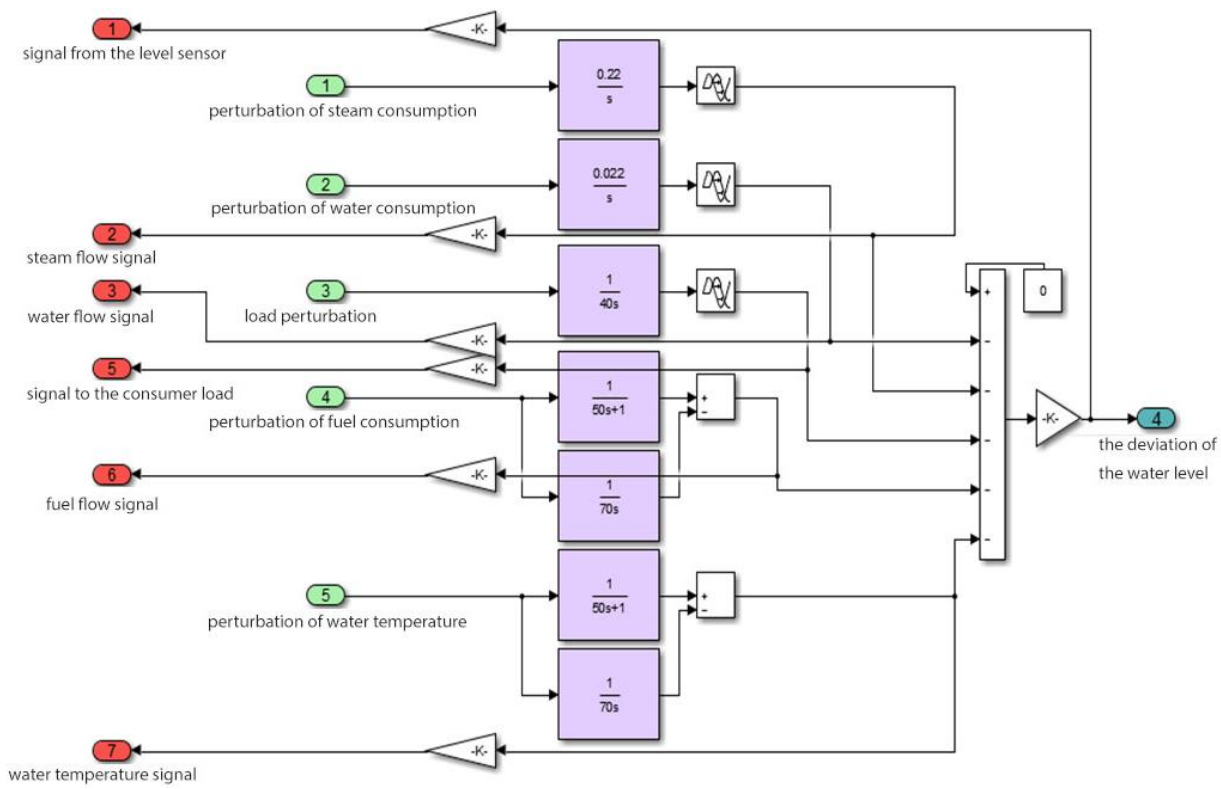

Fig. 12. Boiler drum subsystem.

When testing the model, the abstract controller is replaced by a software PID controller. 


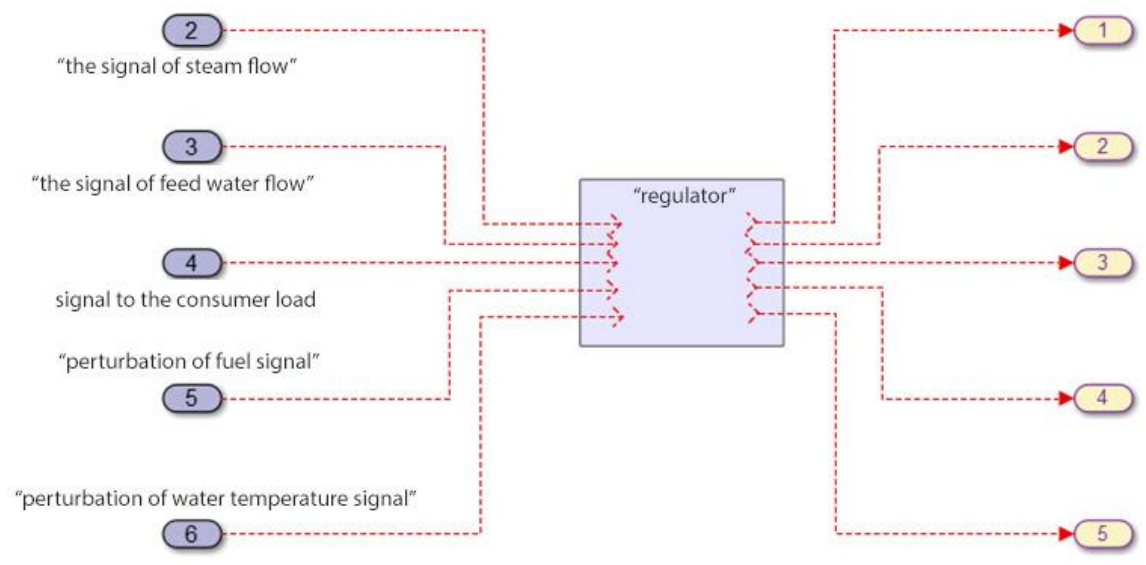

Fig. 13. Subsystem "Controller".

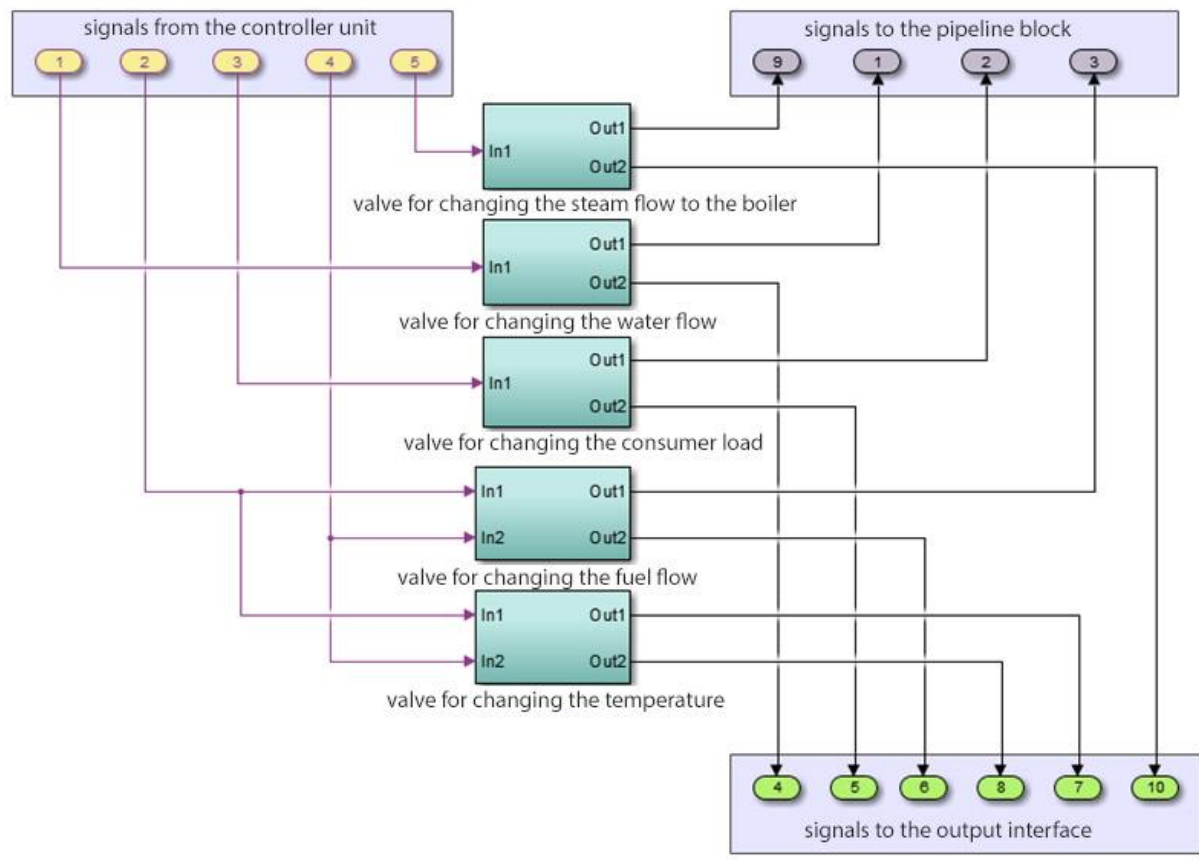

Fig. 14. Valve Block Subsystem.

The "Pipeline" unit completes the model cycle and transmits signals to the control object, which is the "Boiler drum". These outputs capture data on how the system responds to the perturbation. 


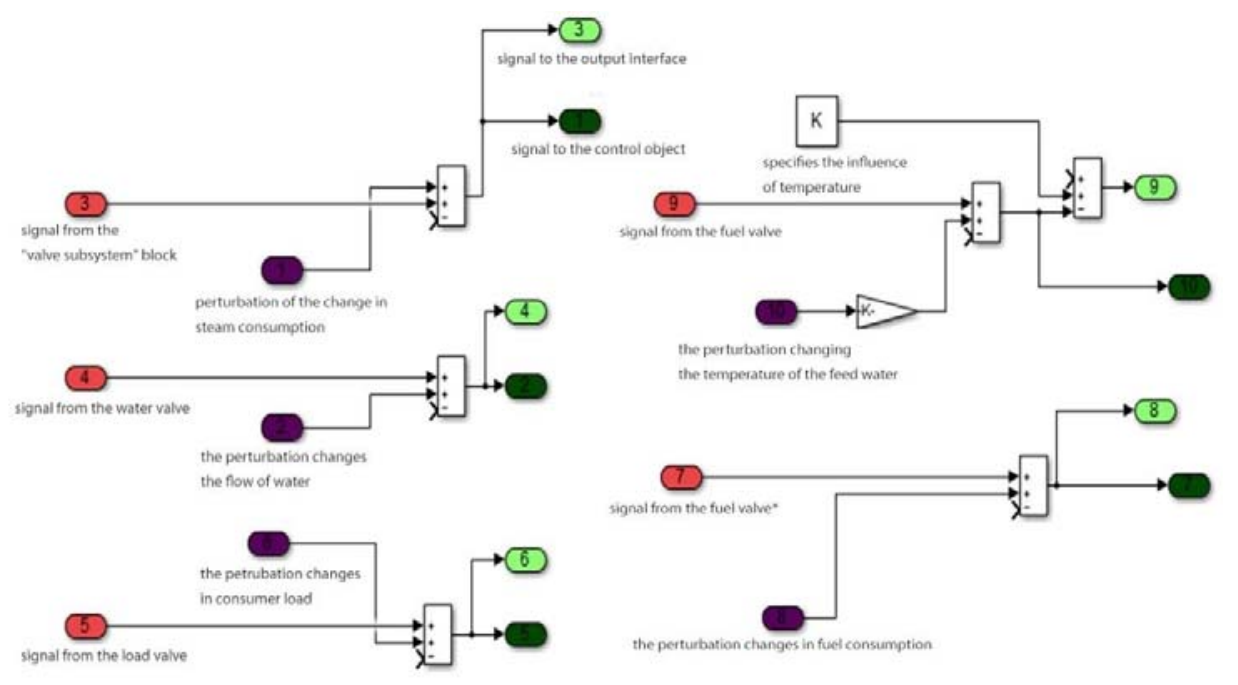

Fig. 15. Pipeline subsystem.

\section{Conclusion}

Theoretical analysis of drum boiler power ARS has been performed. Specificity of power regulation is shown. Transfer functions of control elements are obtained. The analysis of perturbating influences is made. ARS model of drum boiler power supply is constructed.

\section{References}

1. A.F. Shatalov, Modeling in electric power industry: textbook, 140 (2014)

2. S.V. Zvonarev, Fundamentals of mathematical modeling: textbook, 112 (2019)

3. A.I. Gerasimov, Modeling in the MATLAB-Simulink environment: a method. instructions for laboratory work, 104 (2017)

4. A.S. Klyuev, adjustment of automatic control systems for drum steam boilers, 280 (1985)

5. I.F. Kuzmitsky, theory of automatic control: textbook, 574 (2010)

6. G.T. Kulakov, Analysis and synthesis of automatic control systems, 135 (2003)

7. G.T. Kulakov, Engineering Express methods for calculating industrial control systems, 192 (1984)

8. M. Klaučo, M. Kvasnica, Applied Thermal Engineering, 110, 1437 (2017)

9. Y. Gao D. Zeng B. Ping and others, Control Engineering Practice, 102 (2020) 